\title{
Performance Analysis of Routing Protocols in Mobile Wireless Sensor Network
}

\author{
Pallavi S. Katkar \\ Department of Computer \\ Science, Shivaji University \\ Kolhapur, India
}

\author{
Vijay R. Ghorpade, PhD \\ D. Y. Patil College of \\ Engineering and Technology \\ Kolhapur, India
}

\begin{abstract}
A sensor network is nothing but the collection of number of wireless mobile nodes. Each node route the packet as well as forward the packet until the destination. Many routing protocol have been developed in mobile networks. Protocol selection is the main purpose of the wireless network and selected protocol must be best in all aspects of the mobile network. In this paper, simulation performance analysis is carried out on Adhoc On-demand Distance Vector (AODV), Destination Sequenced Distance Vector (DSDV) and Optimized Link State Routing (OLSR) protocol using NS3 simulator. The metrics used for performance evaluation are Throughput, Packet Delivery Ratio and Delay.
\end{abstract}

\section{General Terms}

Purpose of this paper is to cover mobile wireless sensor network routing protocols, Mobile Ad-hoc networks and Network simulator NS3.

\section{Keywords}

Adhoc On-demand Distance Vector (AODV), Destination sequenced Distance Vector (DSDV), Optimized Link State Routing (OLSR) and Mobile wireless sensor network.

\section{INTRODUCTION}

Wireless sensor network consist of number of tiny sensor nodes [1], each node can monitor physical as well as environmental conditions like a change in climate, pressure, temperature, earthquake. There is no standard protocol for mobile wireless sensor network so often protocols are adopted from Mobile Ad-hoc Networks. A sensor network normally constitutes a wireless ad-hoc network, such that each sensor supports a multi-hop routing algorithm and node functions [2]. The idea of ad hoc networking is sometimes also called infrastructure less networking [3]. Protocol selection and routing the path is the main design goal of any wireless network. Routing protocol in mobile ad-hoc network was developed based on the design goals of minimal control overhead, minimal processing overhead, multi-hop routing capability, dynamic topology maintenance and loop prevention [4]. In wireless sensor networks, routing protocol depends according to the selection of network application and routing strategy. Many more routing protocols are available for mobile wireless sensor network out of that AODV, DSDV and OLSR these three protocols are analyzed here with the help of simulation.

\section{ROUTING PROTOCOL}

The main routing protocols are of two types i.e. Protocol operation type and Network structure type. Routing protocol can be classified in to three categories namely, proactive, reactive and hybrid protocol depending on how the source sends a route to the destination [1]. In proactive (table-driven) routing protocol; information broadcast to each neighboring node. Each node keeps information about neighborhood nodes, reachable node and the number of hops in their respective routing table. Each node continuously maintain route between pair of nodes. Reactive (on-demand) this routing protocol called as On-demand protocol because routes are established on demand as they are needed. Once path established; a route is maintain as long as it is needed.

\subsection{Ad-hoc On-demand Distance Vector (AODV)}

AODV is the reactive routing protocol that uses some characteristics of proactive routing protocol i.e., hop-to-hop routing methodology [6] AODV allows for construction of the routes and it is not necessary for other nodes to keep these routes when they are not in active communication. ROUTE REQUEST is used to initiate the route finding process. ROUTE REPLY is used to finalize the routes. When the request reaches a node with route to destination, it creates again a REPLY which contains the number of hops that are requiring the destination. All nodes that participate in forwarding this reply to the source node create a forward route to destination. This route created from each node from source to destination is a hop-by-hop state and not the entire route as in source routing. ROUTE ERROR is used to notify the network of a link breakage in an active route.

\subsection{Destination Sequenced Distance Vector (DSDV)}

DSDV is table driven, hop-by-hop distance vector routing protocol based on Bellman-Ford Routing algorithm [7]. The Main purpose of this algorithm is to solve the routing loop problem. Each node maintains a routing table and each entry in the routing table contains a sequence number, sequence number are generally even if the link is present otherwise odd numbers are used. The stations periodically transmit their routing tables to their immediate neighbors. If some significant change occurs in that case station transmit its routing table for latest updates. So, the update is both timedriven and event-driven. The routing table updates can be sent in two ways: a "full dump" or an "incremental" update.

\subsection{Optimized Link State Routing (OLSR)}

OLSR is an optimization of pure link state algorithm [8] and uses the concept of Multi Point Relays (MPR). MPR are the selected nodes which forward broadcast the message during the flooding processes. This technique reduces the message overhead. In OLSR, link state information only created by the nodes which are elected as MPR and this helps to minimize the number of control message. The MPR node can exchange information links only between itself and its MPR selector. The MPR set is selected such that it covers all nodes that are two hops away. 


\section{PERFORMANCE ANALYSIS OF ROUTING PROTOCOL}

\subsection{Simulation Methodology}

Simulation helps to understand the behavior and performance of the network and its protocol. Many network simulators are available for mobile wireless sensor networks; here NS3Network Simulator3 is used for simulation. In this scenario node 0 is sink node and all other nodes are source node. Random way point mobility model is used for mobile nodes. Behavior of each protocol is compared based on different number of nodes and packets at $11 \mathrm{Mbps}$ Direct Sequence Spread Spectrum (DSSS) Rate.

\subsection{Simulation Parameter}

Parameters are used for simulation to check performance analysis of mobile wireless sensor networks.

Table 1. The Parameters used for the simulation

\begin{tabular}{|c|c|}
\hline Parameters & Values \\
\hline Network Simulator & NS3 \\
\hline Protocol Studied & AODV, DSDV, OLSR \\
\hline Network Type & 1 \\
\hline Node movement model & Random waypoint model \\
\hline Packet Size & $20 \mathrm{~ms}$ \\
\hline Duration & UDP \\
\hline Connection Type & $500 * 500 \mathrm{~m}$ \\
\hline Simulation area & 50 \\
\hline Number of Nodes &
\end{tabular}

\subsection{Performance Metrics}

\subsubsection{Packet Delivery Ratio (PDR)}

Packet delivery Ratio is the ratio between numbers of data packets received by the destination to those generated by the source.

\subsubsection{Throughput}

How much data can be transferred from one location to another in a given amount of time during simulation

\subsubsection{Delay}

The delay specifies the amount of time takes a data packet to reach the destination.

\section{RESULT ANALYSIS}

In this work simulation is carried out on mobile wireless sensor network considering above parameters and performance metrics. Routing protocol used for this work are Ad hoc On-Demand Distance Vector (AODV), Destination Sequenced Distance Vector (DSDV) and Optimized Link State Routing (OLSR)

\subsection{Throughput}

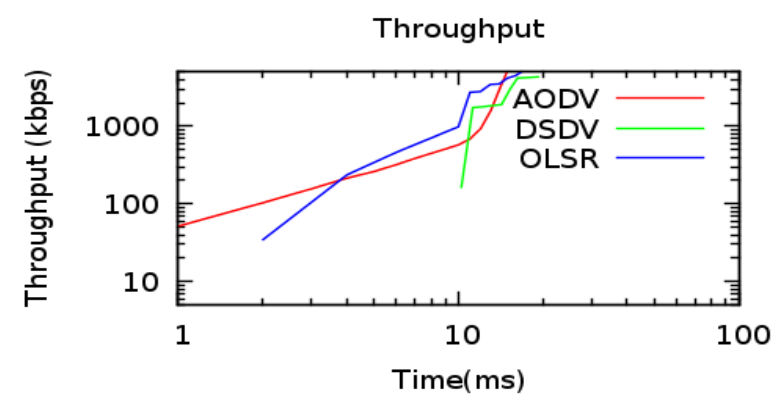

Fig 1: Graph of Throughput

The amount of data transferred from source to destination in given amount of time called throughput. DSDV is the table driven protocol and it takes more time to set up routing table and after that it start delivering the packets to next node. Because of this DSDV provides fewer throughput. Routing protocol OLSR is the proactive protocol and it has many over head due to this OLSR gives minimum throughput. AODV gives better throughput as compare with DSDV and OLSR routing protocol.

\subsection{Packet Delivery Ratio}

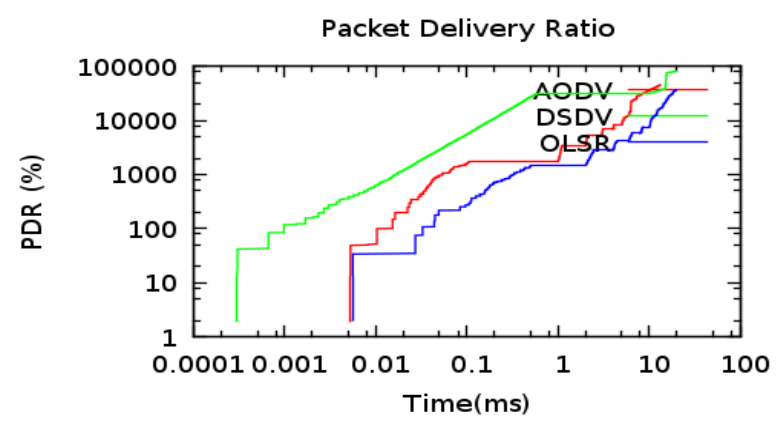

Fig 2: Graph of Packet Delivery Ratio

Packet delivery ratio is the ratio between numbers of the data packet received by the destination to those generated by the source. NS3 simulator got the packet delivery ratio for AODV, DSDV, and OLSR. In AODV destination receives almost all packets send by source. Re-routing is less in AODV so its packet delivery ratio is better than DSDV. OLSR routing protocol performance is well than DSDV.

\subsection{Delay}

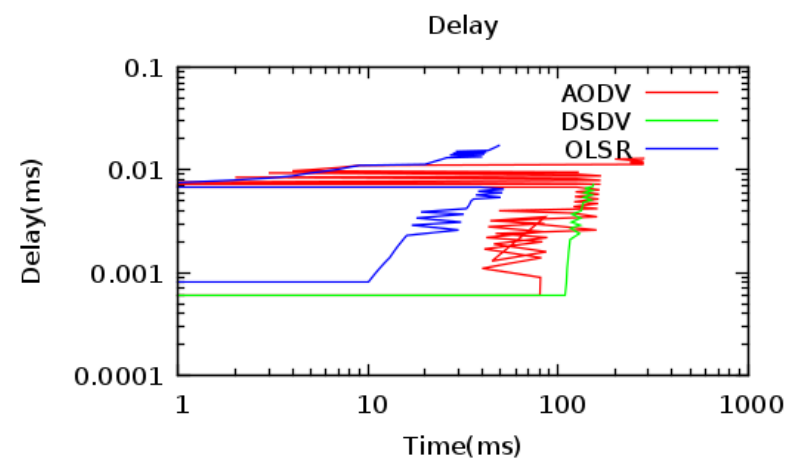

Fig 2: Graph of Delay

Delay refers to the amount of time used by the data packet to transmit across a network from source to destination. DSDV 
routing protocol is the table driven protocol in which all routes are available any time so delay in DSDV is less. In case of AODV routes are determined on demand basis so the delay is more in AODV. OLSR provides the lowest delay because routing table gets updated on regularly. As the routing tables are stored in the table-driven protocol, DSDV could avoid the long set up time caused by changes in network topology. Delay of DSDV is less than AODV. OLSR keep updating routing table regularly and hence provides the lowest delay.

\section{CONCLUSION}

The Mobile wireless sensor network is interesting area for the researcher. It is demanding in various applications. To select appropriate routing protocol is a difficult task. In this paper, we analyzed three routing protocols: Ad-hoc On-demand Distance Vector (AODV), Destination Sequenced Distance Vector (DSDV) and Optimized Link State Routing (OLSR). Network simulator NS3 is used for simulation. Using Throughput, Packet delivery ratio (PDR) and Delay performance metrics and various simulation parameters; carried out the performance analysis for the routing protocol. In simulation result it is observed that AODV provides better throughput compare to DSDV and OLSR. In AODV rerouting is less so gives better PDR than DSDV. In AODV routs are determined on demand basis and hence its delay is more than other two protocols. DSDV is table driven protocol so needs time to routing table setup and provides less throughput and PDR. Proactive routing protocols are having minimum delay because of already stored routing information in routing table hence reduces its delay. DSDV is the proactive protocol and its delay is less. OLSR is a better option than DSDV, provides better PDR and lowest delay.

\section{ACKNOWLEDGEMENT}

Thankful to my guide Dr. Vijay R. Ghorpade and the supporters.

\section{REFERENCES}

[1] P. S. Katkar, V. R. Ghorpade, "A Survey on Energy Efficient Routing Protocol for Wireless Sensor Networks", International Journal of Computer Science and Information Technology", Vol. 6(1), 2015.

[2] A. Goyal, S. Vijay, D. K. Jhariya, "Simulation and Performance Analysis of Routing Protocols in Wireless Sensor Network Using QualNet", International Journal of Computer Application, Volume 52-No.2, August 2012 .
[3] J. Broch, D. A. Maltz, D. B .Johnson, Y.Hu, J.Jetcheva, "A Performance Comparision of Multi-Hop Wireless Ad Hoc Network Routing Protocols", ACM/IEEE, 1998.

[4] E. M. Royer, C. Toh, "A review of current routing for adhoc mobile wireless networks". IEEE personal communications, 1999, pp.46-56.

[5] S. Mohapatra, P. Kanungo, "Performance analysis of AODV, DSR, OLSR and DSDV Routing Protocol using NS2 Simulator", International Conference on Communication Technology and System Design, Published by Elsevier, 2011

[6] C. E. Perkins, E.M. Royer, "Ad-hoc On-demand Distance Vector Routing", draft-ietf-manet-aodv-02.txt, 1998.

[7] C. E. Perkins, P. Bhagwat, "Highly Dynamic Destination-Sequenced Distance Vector Routing (DSDV) for Mobile Computers", SIGCOMM ACM, 1994, pp.234-245.

[8] T. Clusen, P. Jacquet, RFC 3626- "Optimized Link State Routing Protocol (OLSR)”, Oct 2003.

[9] A. A. Chavan, D. S. Kurule, P. U. Dere, "Performance Analysis of AODV and DSDV Routing Protocol in MANET and Modification in AODV against Black Hole Attack", International Conference on Communication, Computing and Virtualization, Published by Elsevier, 2016.

[10] Alexander Klein, "Performance Comparison and Evaluation of AODV, OLSR and SBR in Mobile AdHoc Networks" PP 571-575, 2008 IEEE.

[11] Pallavi Katkar, Vijay Ghorpade, "Comparative Study of Network Simulator: NS2 and NS3", International Journal of Advanced Research in Computer Science and Software Engineering, Volume 6, Issue 3, March 2016

[12] The ns-3 network simulator http://www.nsnam.org

[13] Deepshika Bhatia, Durga Prasad Sharma, "A Comparative Analysis of Proactive, Reactive and Hybrid routing Protocols Over Open Source Network Simulator in Mobile Ad Hoc Network", International Journal of Applied Engineering Research, Volume 11, Number 6, 2016, pp3885-3896

[14] Rakesh Kumar Jha, Pooja Kharga, "A Comparative Performance Analysis of Routing Protocols in MANET using NS3 Simulator", International Journal Computer Network and Information Security, 2016, 62-68 